\title{
El Diario de la Tarde durante la década de 1840. Fait divers, folletín y lectura por entretenimiento en tiempos de Rosas
}

\section{Diario de la Tarde during the 1840s. Fait divers, feuilleton and reading for entertainment in Rosas' times}

\author{
Diego Labra \\ Instituto de Investigaciones en Humanidades y Ciencias Sociales, \\ Facultad de Humanidades y Ciencias de la Educación, \\ Universidad Nacional de La Plata, \\ Consejo Nacional de Investigaciones Científicas y Técnicas (Argentina)
}

\begin{abstract}
Resumen
Es cierto que hitos varios de la "modernización" del periódico porteño deben buscarse hacia el último cuarto del siglo XIX. Sin embargo, esto no significa que no hubiese habido "modernizaciones" previas, en lo que es mejor comprender como un lento y continuo proceso de transformación en las propuestas editoriales de la prensa en Buenos Aires. En particular, los veinte años del Diario de la Tarde (1831-1852) iluminan este proceso, a pesar de presentarse originalmente como otro papel "político y mercantil" y ser encasillado en la bibliografía durante los últimos ciento cincuenta años simplemente como prensa "adicta" a Rosas.

En este artículo argumentamos que este y otros periódicos editados durante los 1840, encarnaron una verdadera renovación formal, en la cual la lectura por entretenimiento funcionó como impulsora privilegiado que solo muy recientemente ha comenzado a ser reevaluado desde la historia de la prensa (Pas, 2016; 2019). Además de presentar y contextualizar la publicación en cuestión, nos enfocaremos en reconstruir la integración a la propuesta editorial de dos recursos concretos que consolidaron un registro nuevo, entretenido, en el diario: los fait divers y el folletín con novelas por entregas.
\end{abstract}

\section{Palabras Clave}

Prensa; lectura por entretenimiento; fait divers; folletín; novela por entregas; Buenos Aires; siglo XIX.

\begin{abstract}
It is true that several milestones in the "modernization" of the Buenos Aires' newspapers should be sought towards the last quarter of the 19th century. However, this does not mean that there had not been previous "modernizations", in what is better understood as a slow and continuous process of transformation in the press' editorial proposals. In particular, Diario de la Tarde (1831-1852) sheds light on this process, despite originally presenting itself as just another "political and commercial" daily, and being desmissed in the
\end{abstract}




\section{Diego Labra}

bibliography for the last one hundred and fifty years simply as a paper "addicted" to Juan Manuel de Rosas.

In this article we argue that Diario de la Tarde, as well as other newspapers published during 1840, embody a formal renovation, in which reading for entertainment functioned as a driver of such renovation, one that only very recently has begun to be reevaluated by press historians (Pas, 2016; 2019). In addition to present and chronollogically contextualize the newspaper, we will focus on reconstructing the integration of two specific resources that cemented a new function, enterteinment, in the newspaper: fait divers and the feuilleton with serialized novels.

\section{Keywords}

Pres; reading for entertainment; fait divers; feuilleton; serialized novels; Buenos Aires; 19 th century.

Sergio Pastormerlo (2016) afirma que alrededor de 1870 se produjo "lo que podríamos llamar la primera modernización de los diarios en Buenos Aires", entendiendo por ello la consolidación de una prensa más comercial que renovó la "confección" de sus páginas, redujo su precio de tapa y adoptó el "sistema de venta por número suelto" para alcanzar autosuficiencia económica (13). Concordamos con este diagnóstico, en tanto y en cuanto una serie de esos hitos "modernos" del desarrollo del periódico porteño se dieron en el último cuarto del siglo XIX (difusión y abaratamiento de la litografía, venta libre "por voceo", salto cualitativo de la publicidad). En esa década nacieron publicaciones que resignificaron lo que se pensaba por impreso exitoso y longevo como, por ejemplo, La Nación (1870).

Sin embargo, esto no significa que no hubiese habido "modernizaciones" previas, en lo que es mejor comprender como un lento pero continuo proceso de transformación en la propuesta editorial de los títulos en circulación. La Gaceta Mercantil (1823-1852), el Diario de Avisos (1849-1852), y en particular el objeto de este artículo, el Diario de la Tarde (1831-1852), son fuentes a menudo citadas, pero poco exploradas, y consideramos que iluminan productivamente el itinerario de ese proceso en la prensa local.

Argumentamos aquí que, en particular, durante los 1840 estos periódicos encarnaron un importante momento anterior del mismo proceso, una verdadera renovación formal en la que la lectura por entretenimiento funcionó como impulsor privilegiado, durante un decenio que solo muy recientemente se ha comenzado a reevaluar desde la historia de la prensa porteña (Pas, 2016; 2019). Como exploraremos a continuación, esta lectura por entretenimiento no se promovió bajo un único soporte, ni de manera progresiva o lineal, sino que la noción fue avanzando discursiva, formal y materialmente de manera irregular, y en zonas en principio impensadas de ciertos impresos; en este caso, en diarios comerciales y políticos.

El artículo, que pretende revaluar una conocida fuente historiográfica bajo una nueva luz, abriendo interrogantes más que cerrándolos, se divide en dos partes. La primera consta de una breve presentación del Diario de la Tarde, tanto formal como 


\section{EI Diario de la Tarde durante la década de 1840. Fait divers, folletín y lectura por entretenimiento en tiempos de Rosas}

histórica, estableciendo una cronología que ayude a contextualizar tanto las singularidades como los rasgos persistentes en la trayectoria del periódico a lo largo del segundo gobierno de Juan Manuel de Rosas en la provincia de Buenos Aires.

La segunda, dividida a su vez en dos partes, se concentra en esbozar lo innovador del repertorio de lectura por entretenimiento introducido por el diario. En especial, dos recursos editoriales concretos: los fait divers, voz francesa traducida como "noticias diversas", los cuales ofrecían una lectura que aspiró a ser tan ágil como capaz de capturar la atención del suscriptor al apelar a su curiosidad e imaginación mediante una escritura breve, dispersa y fragmentaria; y el folletín y la novela por entregas, proceso que, con excepción al trabajo de Hebe Molina (2011), se ha asociado al último cuarto de siglo y que, como se verifica aquí, fue introducido décadas antes.

\section{El Diario de la Tarde y un emergente mundo de entretenimiento urbano}

La publicación comercial Diario de la Tarde fue fundada por Pedro Ponce el 16 de mayo de 1831. El mismo Ponce se desempeñó como jefe de redacción durante buena parte de su andada (Galván Moreno, 1944: 160; Buonocore, 1969: 55 y 56), Sus veintiún años en prensa, desapareció con ese nombre en 1852, lo convierten en uno de los periódicos porteños más longevos del siglo XIX, de los pocos en superar un lustro en prensa. Asimismo, al mantener una frecuencia prácticamente diaria (no salía los domingos), fue junto a El Lucero (1829-1832) de Pedro de Ángelis una de las primeras publicaciones locales en ser distribuida prácticamente todos los días de la semana.

Con sus cuatro páginas de texto abigarrado en cuatro columnas separadas por líneas negras impresas, y las últimas dos carillas reservadas a la inclusión de avisos emitidos por comercios o personas privadas, su diseño tipográfico se ajustó inicialmente a lo que se esperaba de un periódico "comercial, político y literario" durante la década de 1830. Por ejemplo, la disposición de columnas representaba una mayor compresión del texto en relación a las tres del ya citado El Lucero, pero una lectura más aireada contra las seis que alcanzó contemporáneamente La Gaceta Mercantil.

La bibliografía coincide en señalar a 1837 como hito determinante en la larga historia del periódico, año en el cual entró dentro de la esfera del gobierno federal de la provincia de Buenos Aires encabezado por Juan Manuel de Rosas (El Diario. edición extraordinaria, 1933; Galván Moreno, 1944; Buonocore, 1969; Molina, 2009). A este hecho se le atribuye gran poder explicativo, subrayando posteriores rasgos de "adicción" rosista en sus páginas, ya fuera la inclusión obligatoria del encabezado “¡Viva la confederación argentina! ¡Mueran los salvajes unitarios!” (Molina, 2009: 87), o la publicación de canciones en honor de doña Encarnación Ezcurra de Rosas y versos dedicados a Manuelita con motivo de su cumpleaños (Chávez, 1972). El final del impreso también es explicado a través de esta conexión, 


\section{Diego Labra}

estableciéndose una relación directa entre su discontinuación y la derrota de Rosas en la batalla de Caseros, librada el mismo 1852.

La trama de la financiación estatal de la prensa decimonónica está bien documentada (Lettieri, 2006; Molina 2009) y, si bien no existe un estudio que desmenuce particularmente el caso de la publicación de Ponce, en términos generales resulta verosímil que este lazo le habilitara una serie de ventajas a cambio de sostener lo que Buonocore (1969) adjetiva como una "actitud mercenaria" para con el régimen (55). En efecto, solo a través de este hecho es posible explicar la excepcional estabilidad y longevidad que distinguieron al diario, así como al órgano oficial La Gaceta Mercantil, únicos que vieron prensa a lo largo de toda la década de 1840. En el contexto de un mercado editorial aún no consolidado, y especialmente bajo las reglas de juego más restringidas impuestas por el gobierno federal hacia 1838, no existían otras vías posibles para mantener a flote un periódico más que aceptar un apoyo del aparato estatal, que parece incluso haber jugado un rol diferencial en la distribución de los impresos.

La fuente no ofrece evidencia en pos de refutar ese lazo económico y, sí, por momento ideológico. Sino, más bien, su lectura demuestra que éste no agota la complejidad del periódico, el cual cumplió un rol fundamental en la difusión de ciertos recursos formales de la prensa, y ofrece evidencia del proceso sociocultural de tiempos más difusos que refiere a la sociabilidad urbana y el entretenimiento como consumo cultural en general.

El impreso, aquí más como fuente que como "dispositivo" (Pas, 2013), nos habla de este estado de cosas en la ciudad cuando, en ocasión de una despedida a comienzos de 1851, el jefe de redacción reconoce que:

\footnotetext{
“Cuenta para esto, á mas de su contraccion, con los elementos necesarios para su empresa; con buenas suscripciones de periódicos extranjeros; con fuentes seguras que le ministren datos, y con corresponsales activos y puntuales en el exterior.- Su seccion literaria será siempre escogida y digna del interés con que una parte de nuestra sociedad busca en ella un delicado recreo para su espíritu; y todos nuestros lectores serán informados con puntualidad y extension, de todas las novedades diarias, de los espectáculos públicos, de los paseos y de todas las ocurrencias que puedan juzgarse interesantes" (Diario de la Tarde, $\mathrm{N}^{\circ}$ 5.786, 3 de enero de 1851: 1 ; a partir de ahora $D d l T$ ). ${ }^{1}$
}

La cita destaca la vitalidad de un mundo de espectáculos líricos, musicales y dramáticos del cual suele escribirse con más énfasis para las décadas rivadavianas (Guillamón, 2014; Iglesia, 2014). Ya los letrados exiliados denunciaban que, en aquel país que habían dejado atrás, Rosas se divertía en la ausencia de las "luces", pero ¿qué tal si la estabilidad política del rosismo durante la década de 1840 hubiera abierto un espacio para el entretenimiento urbano? Efectivamente, en torno a 1845 prosperaron las instancias de sociabilidad urbana asociada al entretenimiento, desde el juego de la lotería, hasta espectáculos líricos, dramáticos y circenses

\footnotetext{
${ }^{1}$ Todas las citas de las fuentes historiográficas respetan la ortografía original.
} 


\section{EI Diario de la Tarde durante la década de 1840. Fait divers, folletín y lectura por entretenimiento en tiempos de Rosas}

desarrollados por compañías europeas en lugares como el Teatro Argentino o el Teatro de la Victoria, ambos epicentros del mundo cultural del Buenos Aires federal (Gesualdo, 1983: 34).

El escrito del jefe de redacción del Diario de la Tarde invita a preguntarnos por la articulación entre ese efervescente mundo de sociabilidad urbana del entretenimiento y el que ofrecía el periódico. Al listar entre los "elementos" requeridos para la empresa del diario como igualmente "necesarios" instrumentos inherentes a la materialidad de la práctica del periodismo ("buenas suscripciones a periódicos extranjeros", "fuentes" fidedignas), pero también "las novedades diarias de los espectáculos públicos, de los paseos" y todas esas "ocurrencias" que pudieran "juzgarse interesantes", destaca qué tan caros eran esos temas y actividades para el lector de prensa porteño. El entretenimiento se había convertido indudablemente en objeto de interés social, y cabía al periódico comentarlo.

$\mathrm{Si}$, como teoriza Peter Fritzsche (1996), existió durante el siglo XIX una dependencia mutua entre la "ciudad moderna" de "crecimiento inabarcable", donde "la gente, los bienes y la información" fluían cada vez más rápido, y el mundo impreso de las "publicidades urbanas" y los "periódicos" (15), de esa dependencia derivaba tal tematización. Sin la "guía de los periódicos", el lector/ciudadano no podía navegar la ciudad (18). La hipótesis que Fritzsche esboza para las metrópolis de fines del siglo XIX y, sobre todo, de principios del XX, bien podría considerarse a escala si se atiende a los efectos que se verifican en esa tematización del entretenimiento urbano en nuestra fuente.

Más aún, considerando que en el Diario de la Tarde los anuncios de espectáculos musicales, líricos o teatrales, que desde su introducción en los periódicos de los 1820 habían aparecido dispersos entre los clasificados particulares y los policiales (Guillamón, 2014), comenzaron a ser agrupados de manera innovadora en una columna específica, bajo el título de “Diversiones Públicas”, en 1851 (DdlT, № 5.786, 3 de enero de 1851: 1). Reunidos allí cobraban una mayor visibilidad, obtenían cohesión en su variedad y, podemos inferir, iban construyendo el imaginario de ese sintagma, con toda su carga política, colectiva, social: las "diversiones" eran o se leían, ahora, "públicas". La configuración de esta columna propia puede leerse como la consolidación del lugar reservado para esa sociabilidad del entretenimiento y el ocio, novedosamente atada al consumo en el mercado del espectáculo, en un "inventario urbano" de la ciudad que era el periódico fundado por Ponce (Fritzsche, 1996: 18).

En función de esta realidad en ciernes, el diario parece adaptar su propuesta editorial en torno al concepto del entretenimiento, en respuesta a su coexistencia con esta creciente oferta del mundo del consumo y ocio urbano, con la cual competía por el tiempo y el dinero del potencial suscriptor. Para ser "siempre escogida y digna del interés" del lector sabía que debía ofrecerle "un delicado recreo para su espíritu" (DdlT, $\mathrm{N}^{\circ}$ 5.786, 3 de enero de 1851: 1). El impreso contenía temáticamente textos e información sobre entretenimiento, y a su vez, aspiró a entretener por sí mismo. 


\section{Diego Labra}

El periódico de Ponce disputó su lugar en la atención del lector con una oferta editorial que, si bien configuraba un módico mercado, experimentó, como veremos enseguida, un cambio de ritmo durante la década de 1840 ante el desembarco de nuevos textos y formatos. Así como compañías europeas de ópera y circo dinamizaban la oferta y la sociabilidad del consumo de entretenimiento urbano (Aguilar, 2003), la creciente influencia (e importación) de novelas de folletín y la prensa "contaminada" por ella motivaron dentro del periódico la innovación (Pas, 2016: 54; Molina, 2011: 60). En particular, en lo referente a dos recursos formales asociados a la lectura por entretenimiento: los fait divers y el folletín, con su plétora de novelas por entregas.

\section{Un "delicado recreo" para el "espíritu" del lector: I. Fait divers}

Se podría decir que los fait divers, el folletín y las novelas por entregas nacieron juntos en las páginas de dos periódicos parisinos fundados en 1836: La Presse y Le Siècle (Feyel, 2005: 28). Creados respectivamente por Émile de Girardin y Armand Dutacq, fueron concebidos a partir una estrategia comercial novedosa, la cual apostaba a generar rentabilidad reduciendo el precio y aumentando el volumen de ventas (Weill, 1962: 144). Tal como describió Louis Desnoyers, sucesor de Dutacq en Le Siècle, la clave consistía en apelar al "gusto general" de un público lector cada vez más expandido y menos preocupado por las urgencias políticas (Citado en Pas, 2016: 54). Con este fin se orientó la escritura hacia una zona de "contaminación novelesca” y literaria (Molina, 2011: 60), "un espacio para la experimentación, la reapropiación discursiva y, en consecuencia, la invención escrituraria" (Pas, 2016: 55), donde "variedades (varietés), misceláneas (mélanges) y folletín (feuilleton)" fueron términos intercambiables (54).

Como refleja la historia, estos recursos fueron concebidos como parte de un repertorio específicamente dirigido a introducir la lectura por entretenimiento en la propuesta editorial de la prensa. Se exploró una escritura que tomó elementos de la "narración novelesca" como el "ritmo narrativo ameno", el uso de "diálogos" y la administración de "expectación dosificada", todo en la aspiración de seducir a la mayor cantidad de público posible con la promesa de diversión (Molina, 2011: 60). Este mismo origen común dificulta precisiones y cronologías, pues la separación entre uno y otro era "característicamente ambivalente", incluso derramándose como vimos la "contaminación" a todo rincón del diario (Pas, 2016: 54). Por ejemplo, el título "fait divers" apareció por primera vez como expresión de "noticia" en la "vieja prensa diaria" francesa a finales de 1833, mas lo que hoy entendemos por ese recurso editorial tomó forma unos años más tarde en los mencionados periódicos comerciales y masivos de París (Feyel, 2005: 28).

En nuestra fuente se comprueba el problema, siendo difícil puntualizar fechas precisas para la consolidación de recursos formales a lo largo de una serie muy larga (y, por demás, llena de huecos en los repositorios documentales). Lo acotado de la bibliografía actual sobre este tema en la prensa decimonónica nos obliga a pensar 


\section{El Diario de la Tarde durante la década de 1840. Fait divers, folletín y lectura por entretenimiento en tiempos de Rosas}

su desarrollo con pocas certezas, siendo acaso la única de ellas que la noción de "variedades" existió en la prensa porteña prácticamente desde su concepción (Goldgel, 2010; Pas, 2016). ${ }^{2}$ Mas, reconociendo este difuso panorama, afirmamos que durante la década de 1840 el despliegue de los fait divers alcanzó un momento consolidatorio en el diario de Ponce, un paso intermedio entre la exploratoria "contaminación novelesca" de largos textos noticiosos que Pas (2016) distingue en los periódicos de los 1830, y la producción local de "hechos diversos" divertidos o sorprendentes que Schvartzman (2013) encuentra veinte años más tarde.

Dos son las razones, relacionadas entre sí, en que nos apoyamos para hablar de consolidación: primero, su recurrencia, mediante la cual se convirtió en parte permanente de la propuesta editorial; y segundo, al afianzamiento de la causalidad aberrante y autonomía narrativa como características de los textos a partir de su configuración como entradas breves, diversas y fragmentarias.

Dicho esto, el recurso no apareció completamente formado en el Diario de la Tarde, sino que, de la misma manera en que fue desarrollándose paulatina e irregularmente en la prensa porteña, se desenvolvió en el impreso a lo largo de la década, yendo del ocasional "Extracto de periodicos extrangeros" en 1838 a las "Noticias diversas" o "varias" diez años después. ${ }^{3}$

\footnotetext{
2 Víctor Goldgel (2010) identifica el uso del título "Variedades" tan temprano como 1826, en El Mensagero Argentino (1825-1827), y sugiere que el principio de diversidad temática detrás de estas se podría rastrear hasta el fundacional El Telégrafo Mercantil (1801-1802) (277). Por su parte, Hernán Pas (2016), señala como una "primera incursión" de la "novelización" de noticias en las publicaciones rioplatenses una crónica judicial publicada en El Defensor de las Leyes de Montevideo en septiembre de 1836 (56). Por último, Julio Schvartzman (2013) atribuye correctamente a Estanislao Del Campo la autoría de la primera columna de "Hechos diversos" escrita íntegramente para una publicación de Buenos Aires, aparecida en Los Debates de Bartolomé Mitre desde agosto de 1857 (266).

${ }^{3}$ Hacia 1838 comenzaron a publicarse ocasionalmente largos textos importados afines a un espíritu "novelesco" propio de la prensa contemporánea europea, mayormente en la sección "Extracto de periodicos extrangeros". En 1841, dichos escritos fueron agrupados bajo las etiquetas alternativas de "Miscelanea" (DdIT, № 2.960, 9 de junio de 1841: 2) o "Noticias diversas" (DdIT, N $N^{\circ} 3.007,7$ de agosto de 1841: 2). Continuaron apareciendo de este modo durante los siguientes años, de manera errática e imprevista, bajo el título de "Misceláneas" (DdlT, $\mathrm{N}^{\circ}$ 3.168, 1 de marzo de 1842: 1), "Noticias diversas" (DdIT, $\mathrm{N}^{\circ}$ 4.700, 24 de mayo de 1847: 1), "Variedades" (DdlT, $\mathrm{N}^{\circ} 4.942,14$ de marzo de 1848: 1), o "Noticias Varias" (DdlT, No 5.164, 14 de diciembre de 1848: 1), aunque lo publicado solo de manera ocasional, difería formalmente de lo que podía leerse en las extensas entradas de "Extractos de Diarios Extrageros".
} 


\section{Diego Labra}

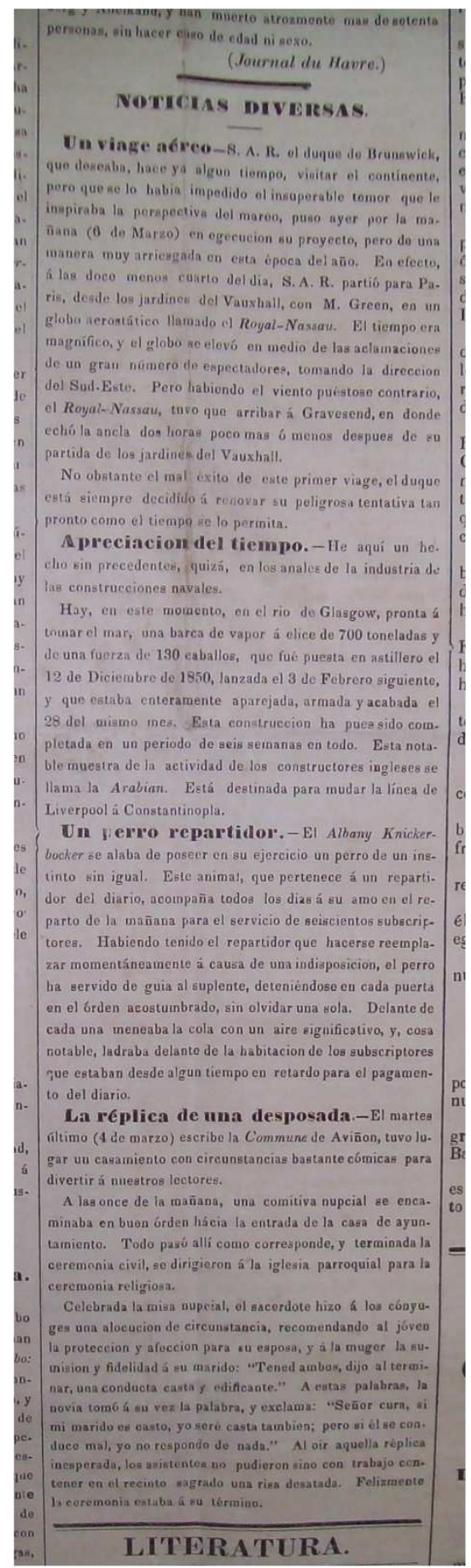

Fragmento de página extraído de DdlT, N⒌915, 6 de junio 1851: 1.

En 1851, durante su último año completo en prensa, los fait divers alcanzaron una forma definitiva en el diario. Según fuentes secundarias, y en el marco de la venta del periódico por parte de Ponce a otro propietario $\left(D d l T\right.$, $\mathrm{N}^{\circ} 5.786,3$ de enero de 1851: 1), se puso al "periodista profesional" Federico de La Barra a la cabeza de la redacción (Galván Moreno, 1944: 160; Buonocore, 1969: 55 y 56). En este contexto, las "Noticias Diversas" (DdIT, $\mathrm{N}^{\circ} 5.872,15$ de abril de 1851: 1), y ocasionalmente las "Variedades" (DdlT, $\mathrm{N}^{\circ}$ 5.905, 26 de mayo de 1851: 1) se convirtieron en una parte 


\section{EI Diario de la Tarde durante la década de 1840. Fait divers, folletín y lectura por entretenimiento en tiempos de Rosas}

integral de la propuesta editorial. En columnas con varias entradas, de nunca más que un puñado de párrafos, el lector podía entretenerse leyendo en un solo ejemplar acerca de cuestiones tan diversas como la "invención extraña" de una "casa ambulante" por un ingeniero norteamericano; un breve perfil del ejército chino con sus "trages pintorescos en rostros de color de cera, [que] forman una vista salvage y extravagante", y la reproducción de una nota del New York Herald donde se explora la idea de Mr. Wise y Mr. Tagget de "nadar en los aires" mediante un globo aerostático (DdIT, $\mathrm{N}^{\circ}$ 5.821, 13 de febrero de 1851: 1).

Estos ejemplos ilustran como (casi) todos los textos publicados entre las "Noticias Diversas" podrían clasificarse dentro el universo temático que Roland Barthes (2003 [1964]) atribuye en su clásico estudio sobre los fait divers: historias sobre lo asombrosa capacidad de la ciencia para inventar nuevos artefactos como "telégrafos" que permiten comunicarse "entre un sordo mudo y un ciego" $\left(D d I T, \mathrm{~N}^{\circ}\right.$ 5.947, 15 de julio 1851: 1), relatos sobre tragedias como "Horrible naufragio del Atlantic" (DdlT, N 4.748, 24 de julio de 1847: 1), o crímenes horrendos como "Infanticidios múltiples" ( $D d l T, \mathrm{~N}^{\circ} 4.846,28$ de diciembre de 1847: 1). Relatos como aquel del "ahorcado mal ahorcado" (DdIT, N 5.905, 26 de mayo de 1851: 1 y 2), cuya narración entre el terror y el humor negro sobre las desventuras del "doctor FaustWerther, de Stuttgard" combinan elementos de los tres anteriores, subrayando hasta qué punto el contacto con lo literario de estos textos se mantuvo intacto en el viaje trasatlántico al narrar. Lo que podríamos llamar, con ciertos recaudos, una "contaminación novelesca" de segunda mano de la prensa porteña.

A la dispersión temática y narrativa de aspiración literaria que había caracterizado hasta entonces a las redacciones incluidas en el periódico, se sumaron dos características importantes, particularmente en las "Noticias Diversas": la recurrencia del recurso, y brevedad de las entradas. Se redujeron sistemáticamente cada una a un puñado de renglones en la angosta columna, escritas de manera tan concisa como atractiva. Lo suficiente para capturar la atención del lector, sin retenerla excesivamente (es decir, sin exigirle detenerse en explicaciones ulteriores, o en la necesidad de rememorar información adicional). La condensación, además, permitió que múltiples entradas convivieran en una columna.

Para mediados de 1851, la redacción solo necesitaba apenas más de cien palabras para contar la historia de "un viage aéreo" realizado en "globo aerostático" por el "duque de Brunswick" desde "los jardines de Vauxhall" en Inglaterra hasta París, una "barca de vapor á elice (sic) de 700 toneladas y una fuerza de 130 caballos" construida "en el rio de Glasgow", o un sorprendente "perro repartidor" en Albany, New York (DdlT, № 5.915, 6 de junio 1851: 1):

Este animal, que pertenece á un repartidor del diario, acompaña todos días á su amo en el reparto de la mañana para el servicio de seiscientos subscriptores. Habiendo tenido el repartidor que hacerse reemplazar momentáneamente á causa de una indisposición, el perro ha servido de guia al suplente, deteníendose en cada puerta con el órden acostumbrado, sin olvidar una sola. Delante de cada una meneaba la cola con un aire 


\section{Diego Labra}

significativo, y cosa notable, labraba delante de la habitación de los suscriptores que estaban desde algún tiempo en retardo para el pagamento del diario (DdlT, $\mathrm{N}^{\circ} 5.915,6$ de junio 1851: 1)

Barthes (2003) define a los fait divers como "una información total, o, más exactamente, inmanente; [que] contiene en sí todo su saber" (260). La información es "del mundo", no deja de estar sujeta al contexto de donde fue extraída, pero "se trata de un mundo cuyo conocimiento siempre es sólo intelectual, analítico, elaborado en segundo grado por el que habla del suceso, no por el que se lo consume" (261). Cada entrada aspira así a ser entonces una "información total", que para ser consumida por el lector no demanda de él ningún conocimiento adicional (no requiere de competencia enciclopédica ulterior) ni de la lectura de otros textos que lo acompañen. Partiendo del repertorio temático de lo singular y extraño centrado en el crimen, las catástrofes y lo "extravagante" (264), el "suceso" se construye en una disparidad donde "todo se da al nivel de la lectura", "sus circunstancias, sus causas, su pasado, su desenlace; sin duración y sin contexto". El fait divers constituye así "un ser inmediato, total, que no remite, al menos formalmente, a nada implícito", cual "novela corta" o un "cuento" (261).

Abigarradas en un párrafo, y separadas por un espacio en blanco, como en el ejemplo reproducido, cada entrada logró conservar la dimensión narrativa y hasta literaria descrita por Barthes y Pas, y en ella se condensa como una "información total" que no demandaba más para ser leída, pero al mismo tiempo fue reducida a su menor expresión posible, para agilizar su consumo. En la combinación dentro de cada columna de una diversidad de temas inconexos, desde la maravilla técnica de los "globos aerostáticos" y las "casas ambulantes" hasta el costumbrismo de los "trajes pintorescos" chinos, el asombro entendido como diversión en la lectura solo se multiplican en el contraste, alimentándose uno del otro.

Este aspecto del recurso formal, como textos autosuficientes, es interesante porque rompe con la frondosa "interdiscursiva" del debate político que era la norma de la prensa diarística. En las columnas misceláneas se ofreció información provista por "causalidad aleatoria, coincidencia ordenada", emparentada al "estatuto" de la literatura (Barthes, 2003: 271). A la prosa argumentativa que hacía fluir los debates de la opinión pública a través de páginas y páginas de editorialismo, estas oponen una escritura breve, punteada, sintética, fragmentaria. Textos que aspiraban a proporcionar un consumo fácil, que proveyera satisfacción inmediata en lo autocontenido de su sentido, y entretuviera lo suficiente para producir el deseo de seguir leyendo. Las "noticias diversas" aparecen, entonces, como el epítome de la "legibilidad" (Sarlo, 1985: 14), entendida como la facilidad de acceso a los textos y su lectura.

Asimismo, la proliferación de escritos importados da pie a pensar en una progresiva "extranjerización" de los contenidos resultado de un contexto específico. Si bien las "valijas de información miscelánea" que arribaban al puerto en vapores transatlánticos siempre había sido una parte importante de los periódicos porteños, única fuente de noticias extranjeras antes del tendido del "ansiado cable 


\section{EI Diario de la Tarde durante la década de 1840. Fait divers, folletín y lectura por entretenimiento en tiempos de Rosas}

transatlántico Lisboa-Pernambuco" en 1874 (Caimari, 2015: 128), en el caso específico del diario de Ponce parece haber jugado un rol excepcional ante las circunstancias específicas del éxodo político de buena parte de los letrados que hasta esa fecha escribían en la prensa hacia 1838 (Galván Moreno, 1944; Buonocore, 1969).

Es cierto, también, que subrayar el pragmatismo de las redacciones a la hora de configurar el periódico con lo que tuvieran a su disposición no significa negar la agencia de los actores porteños de la prensa, fueran redactores o impresores. Eran ellos los últimos árbitros de lo que terminaba en la página, como lo explicita el mismo responsable del Diario de la Tarde al informar en cierta edición que los lectores no encontrarían textos propios de los "periódicos de Paris", pues entre lo recibido que "alcanz[ó] al 12 de Junio" no hubo nada de "interes" (DdIT, N 3.024, 27 de agosto de 1841: 2). Es decir, la transformación identificada en la propuesta editorial del Diario de la Tarde a lo largo de la década puede entenderse como resultado tanto de circunstancias históricas y la agencia del editor, que conspiraron para "traficar" cierto grado de "contaminación novelesca" importada desde Francia, Inglaterra o Estados Unidos.

Este giro hacia lo conciso y fragmentario de los fait divers también ayudó a que estos se distinguieran de otros textos o recursos tocados por la "contaminación novelesca". Tal diferenciación ayudó a asentar un lugar para el recurso dentro de la propuesta editorial en la que avanzaba otro producto de aquella "contaminación": la novela de folletín.

\section{Un "delicado recreo" para el "espíritu" del lector: II. folletín y novelas por entregas.}

Como señalamos antes, el folletín y la novela por entregas tuvieron en la prensa europea el mismo origen en esa zona indiferenciada de la "contaminación novelesca" (Pas, 2016; Molina, 2011). Pero a diferencia de los fait divers, el romanfeuilleton se configuró como un espacio con entidad propia dentro de la página, separado del resto de los textos por medios tipográficos: líneas negras, cuerpo o tipo de letra distintivos, u otros. Es decir, fue "un lugar preciso del periódico"; ese "zócalo" que se ubicó en la parte inferior de la página, y como toda novedad significativa, generó una serie de palabras nuevas. Aquello que los franceses llamaron "rez-de-chausée" cuando Dutacq lo inventó junto con Alexandre Dumas, padre, en Le Siècle, y que los españoles tradujeron como "rodapié". También conllevó una temporalidad específica, una aparición semi regular obligatoria de la serialización (Pas, 2016: 55).

La salva inicial la disparó Dumas, quien publicó "Le Capitaine Paul” entre el 30 de mayo y el 23 de junio de 1838 (Pas, 2016: 55). Los clásicos llegaron unos años luego: "Los Misterios de Paris" aparecieron en el Journal des Débats entre junio de 1842 y octubre de 1843, y "El Judío Errante" en Le Constitutionnel en 1844, ambos de Eugène Sue. Ese mismo año, Dumas publicó “Los Tres Mosqueteros” en Le Siècle y 


\section{Diego Labra}

“El Conde de Montecristo" en el Journal des Débats (Pas, 2018: 194). El éxito de estas obras y el formato folletín garantizó que se difundieran velozmente por toda Europa y sus colonias, circulando según el contemporáneo Ballanche "más rápidamente que el cólera" (Weill, 1962: 146).

En Buenos Aires, el principal vehículo de difusión de las novelas francesas fue el Correo de Ultramar, fundado en Paris durante 1842 por Xavier de Lasalle como un emprendimiento comercial con miras a toda la América hispanoparlante (Pas, 2018: 198). Estas fueron parte del folletín de dicha publicación, pero también se las vendió por separado en diferentes modalidades como folletos por entrega, promocionándose en diversos diarios la serialización de El Judío Errante, Los Misterios de París o Los Misterios de Londres de Paul Féval (201).

A lo largo de la década, se fue delineando un circuito de la novela de folletín en la capital, que seguía más o menos siempre un sentido de circulación similar: una obra europea era licenciada por un actor intermediario, como la imprenta de de Lasalle, que supo establecer contratos exclusivos para la comercialización en América entera (Pas, 2018: 202). Ya en el Nuevo Mundo, los impresos eran distribuidos en cada ciudad cabecera a través de una red de agentes, "en su mayoría burgueses ilustrados, libreros, militares reconocidos, diplomáticos o periodistas" (207). La literatura folletinesca francesa se difundía luego mediante "aventuras editoriales privadas" emprendidas por las imprentas porteñas que poco distaban de la "piratería" (202). El resultado fue un verdadero "boom editorial", como lo adjetiva Pas, que avivó "la especulación comercial de las imprentas locales de un modo que hasta entonces no lo había hecho ni siquiera la aparición de las Rimas de Esteban Echeverría" (210).

Un ejemplo es la primera edición local de los "Misterios de Paris", por la imprenta de la Librería y Litografía Argentina de Gregorio Ibarra, aparecida solo diez días después que fueran impresos los avisos del Correo de Ultramar, y que se reconoció "reimpresa y corregida" de las "traducciones españolas que ya circulaban en Buenos Aires", probablemente en un plagio de la edición de la imprenta Saurí de Barcelona (Pas, 2018: 203). Debido a la distancia que separaba a la capital del Viejo Mundo, la reproducción de estas obras se hizo de forma ilegal y gratuita (203 y 204).

No fue casual que cuando los impresores porteños decidieron publicar novelas de folletín, se volcaron por los mismos títulos importados por esa editorial, en la mayoría de los casos impresos con pocos meses de diferencia a la aparición original. El desembarco en la ciudad de los productos de Xavier de Lasalle en 1945 posibilitó la circulación de ediciones autóctonas en folleto o fascículo, siendo la citada edición de Ibarra solo un ejemplo entre muchos. Solo entonces fue posible que el feuilleton debutara en la prensa local, como un lugar preciso y habitual en la propuesta editorial.

La aparición en el Diario de la Tarde de la entrega inaugural del "El Judío Errante" de Eugène Sue el 16 de marzo de 1846 convirtió al periódico en el primero en incluirlos en Buenos Aires (DdlT, $\mathrm{N}^{\circ}$ 4.349, 16 de marzo de 1846: 1). Su introducción del "rodapié" representó una transformación desde lo tipográfico en la prensa diaria 


\section{EI Diario de la Tarde durante la década de 1840. Fait divers, folletín y lectura por entretenimiento en tiempos de Rosas}

porteña. Delimitó un espacio nuevo, demarcado por una línea en la parte inferior de la primera página, que ocupaba aproximadamente un tercio de la misma y continuaba la organización de texto en cuatro columnas. Además, el aspecto de la serialización demandó de la redacción un compromiso de regularidad y estabilidad en la propuesta editorial, un prospecto difícil de mantener en el inestable mundo editorial del siglo XIX.

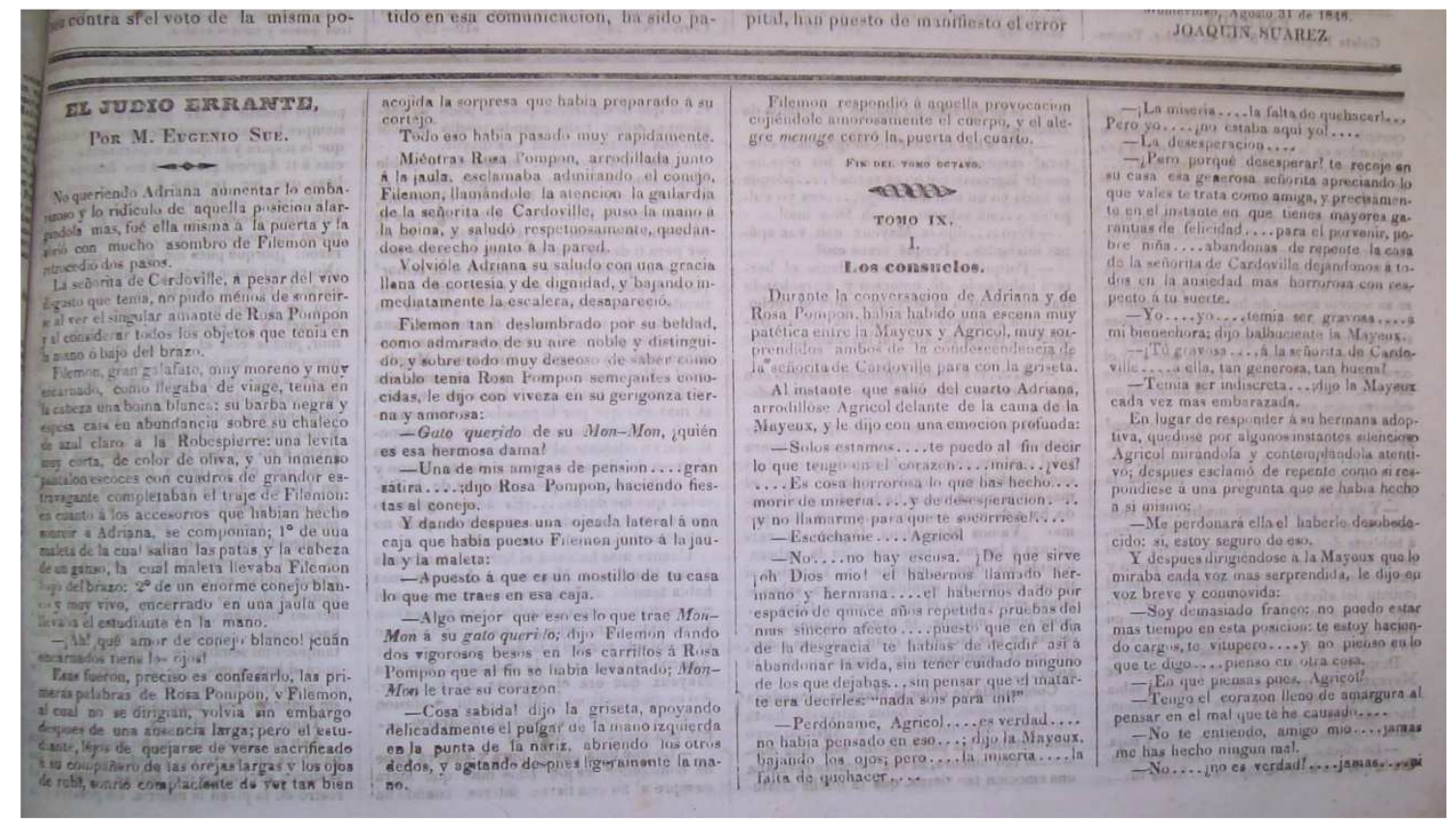

Fragmento de página extraído de $D d l T, N^{\circ} 4.491,10$ de septiembre de 1846: 1.

La consolidación en la prensa de la novela-folletín -como rincón tipográfico diferenciado- definió su contenido, y se consagró como un espacio de lectura por entretenimiento. Si bien es cierto que el interior del folletín se asocia a "toda clase de textos literarios", como "poemas, dramas, relatos de viajes y ensayos" (Molina, 2011: 28), la novela por entregas fue el único contenido impreso en el zócalo del Diario de la Tarde, y probablemente una de las razones de su éxito. La aparición, menos de quince días luego, de un segundo folletín, "Album Universal", esta vez ocupando la mitad inferior de las páginas posteriores a ambos lados de la hoja y listo para recortar, puede interpretarse como un claro indicador de la buena recepción que tuvo la iniciativa por parte de los suscriptores (DdIT, $\mathrm{N}^{\circ} 4.359,28$ de marzo de 1846: 3 y 4). Más todavía teniendo en cuenta que debutó como un complemento del día sábado, para luego aparecer también de manera irregular el resto de los días de la semana ( $D d l T, \mathrm{~N}^{\circ} 4.372,15$ de abril de 1846: 3 y 4).

En la intersección entre los títulos importados desde ultramar y la bien documentada afinidad de los letrados de Buenos Aires por la producción europea, particularmente la novela histórica francesa (Laera, 2003; Espósito, 2009), encontramos las razones detrás de la selección de obras publicadas en el Diario de la Tarde. El mismo Pedro Ponce reconoció que el gusto europeizado y la fama que 


\title{
Diego Labra
}

ya gozaban estos escritores en Buenos Aires fue un factor de peso en sus decisiones editoriales ( $D d l T$, $\mathrm{N}^{\circ} 4.930,28$ de febrero de 1848: 2). ${ }^{4}$

Justamente, la publicación de una novela de Dumas, "Dos Dianas", ejemplifica concretamente la importancia que alcanzó el folletín en el Diario de la Tarde. La ausencia de la novela del zócalo delantero, así como del folletín de la página trasera, a fines de 1848 resultó un hecho lo suficientemente grave en la apreciación de la redacción, que interpela a sus suscriptores con un mensaje solemne:

\begin{abstract}
Saldrá la próxima publicación que tenemos el gusto de anunciarles bajo el nombre de DOÑA BLANCA DE NAVARRA, que nos ha llegado últimamente de Madrid, escrita en nuestro idioma originario por el célebre D.F. NAVARRO VILLOSLADA, publicada en España. El entusiasmo con que ha sido recibida y reimpresa en Europa, sale garante de su mérito; pues la fluidez de lenguaje y dulzura de su estilo, la ponen al nivel de las mas celebradas obras de literatura de que hemos tenido conocimiento en esta ultima serie; seguros de que los SS. Suscriptores á las DOS DIANAS sabrán apreciar y distinguir lo mismo á DOÑA BLANCA DE NAVARRA, en la que tenemos la ventaja de no sufrir el desmerecimiento ó los deslices de una versión, porque rara vez se expresan las ideas de un autor, ni el selecto lenguaje de la inspiracion original, en la traduccion de un idioma (DdlT, $\mathrm{N}^{\circ} 5.164,14$ de diciembre de 1848: 1).
\end{abstract}

Primero, la intención del redactor por resaltar el carácter importado, extranjero de la obra queda clara en la reiteración del origen en el lapso de dos oraciones como oriunda de "Madrid", de "España" y de "Europa" también. En la igual de insistente vocación por destacar "la fluidez de lenguaje y dulzura de [un] estilo" que provenía directamente de la pluma del autor y no de la "traduccion de un idioma", lo que puede interpretarse como una defensa preventiva de la publicación de una novela ibérica en lugar de francesa, que había sido exclusivamente el caso de las "mas celebradas obras de literatura" que componían la "serie" del diario.

Segundo, la rápida respuesta de la redacción a esta contingencia, la obligación que sintió para, primero, publicar un aviso aclaratorio y, después, solucionar el conflicto al solventar un suplemento creado expresamente para hacer llegar las entregas a los lectores, a quienes no se les cobró un real de más, indica la importancia que había alcanzado la novela en el periódico. El editorial donde el responsable del diario se excusaba por el cambio y, además, promocionaba la próxima aparición "Doña Blanca de Navarra" de D.F. Navarro Villoslada, publicada en España" (DdlT, № 5.164, 14 de diciembre de 1848: 1), funciona como un reconocimiento explícito de en qué medida el folletín había devenido en una pieza insoslayable de la propuesta editorial. Solo bajo la hipótesis de que la ausencia de la novela reportaría un daño económico significativo a los productores, es decir, que un gran número de sus suscriptores

\footnotetext{
${ }^{4}$ Acaso el escritor más publicado en el periódico fue Alexandre Dumas, cuyas obras siempre fueron destacadas por la redacción como trabajos del "célebre escritor francés", cuando no traducidas desde ese idioma y como integrantes del género histórico. La popularidad de la prosa de Dumas incluso excedió los confines del folletín, apareciendo en más de una ocasión textos por el firmados en otras secciones, como "El Asalto de Constantina" ( $D d I T, \mathrm{~N}^{\circ} 5.898,17$ de mayo de 1851: 1), o "Árabes y Franceses" (DdIT, N 5.915, 6 de junio de 1851: 1).
} 


\section{EI Diario de la Tarde durante la década de 1840. Fait divers, folletín y lectura por entretenimiento en tiempos de Rosas}

dejaría de comprar el diario en la ausencia de las "Dos Dianas", se justificaba absorber completamente el costo de continuar publicando la obra al ritmo de "ocho páginas diarias" adicionales "separadamente del Diario", cuando la publicación constaba de solo cuatro.

Impresores y jefes de redacción porteños utilizaron discrecionalmente el término "novela" (Molina, 2011: 56), menos interesados en el acto de clasificar una producción literaria que por conjurar el poder de atracción que ejercía sobre el potencial suscriptor las lecturas consideradas más "amenas" o "ligeras" (Pas, 2016: 56). Es decir, a diferencia del resto del periódico, donde se pugnaba por opinar, informar, discutir y conquistar la racionalidad de los lectores, era un acuerdo tácito que dentro del folletín las reglas eran diferentes. La prensa y concretamente, el diario, albergaba así un doble régimen de apelación, distinguido en su puesta en página.

La modalidad de la publicación por entregas, además de obedecer a obvias imposiciones materiales que hacían imposible insertar un texto narrativo largo entero en una publicación de cuatro páginas, tuvo como efecto colateral adaptar su lectura a la propuesta editorial de un periódico que aspiraba, entre otras funciones, a entretener. Al parcelar la obra, que usualmente acumulaba decenas o cientos de páginas, se disponía su consumo más inmediato, menos demandante de tiempo, y se predisponía a una lectura extensiva que podía alternar entre varios textos a la vez (Chartier, 1994).

Sin embargo, la naturaleza serializada de la novela por entregas también contenía en sí la posibilidad de una lectura más pendiente y podía atrapar al lector con cada “continuará...", manteniéndolo cautivo hasta la próxima entrega. Es esta lectura más intensiva la que fue materializada en el acto de recortar, guardar y perpetuar las obras literarias como un volumen completo y acabado al alcance del lector. Si bien la ausencia de evidencia de tales colecciones en nuestro país nos impide afirmar que lectores compilaran las entregas, si se han conservado en las hemerotecas los ejemplares del Diario de la Tarde (y el posterior Diario de Avisos) con las entregas de los folletines recortadas. Esta es la única intervención de los lectores de la que tenemos fehaciente evidencia, y por lo tanto nos ofrece la posibilidad de pensar la lectura como práctica sobre una base firme.

Ensamblar las entregas sueltas en una obra reunida no solo destruía al periódico diario, el cual ya entonces parece haber sido producido y comprado en concepto de consumo descartable, sino que también potencialmente transmutaba una serie de lecturas breves y fragmentadas en otra igual de entretenida pero que demandaba un consumo cualitativamente diferente. Esto fue tan cierto para los folletines dispuestos a tal fin, ubicados en la parte trasera del diario con un diseño que imitaba los pliegos de un libro, como para el zócalo de la primera página que, a pesar de no estar acondicionado para ello, era igualmente recortado.

Calibrar el impacto de la novela de folletín y las nuevas formas de leer por entretenimiento que ofreció en Buenos Aires nos enfrenta ante una tarea difícil. Es claro que las condiciones económicas, sociales y culturales de la ciudad distaban de 


\section{Diego Labra}

aquellas de las capitales europeas, donde las obras de Sue y Dumas eran un éxito sin precedente. La prensa porteña tampoco podía si quiera soñar con replicar los números de ventas alcanzados por La Presse y Le Siècle en Paris. Sin embargo, difícilmente esta actividad editorial se hubiese difundido con la premura que reflejan los avisos publicitarios de no existir una respuesta favorable del público. Con seguridad puede aseverarse que este auge desestima la imagen de la década de 1840 como un "período sombrío" que habría ahogado el mundo del impreso hasta Caseros presente en la bibliografía clásica (Buonocore, 1969: 10) y, en su lugar, ofrece el retrato de un vivaz circuito editorial articulado en torno a la novela de folletín.

La pluralidad de modalidades de venta (libro, fascículo por suscripción, folletín del periódico) ofrecía a los lectores una variedad de opciones, al tiempo que incentivaba la retroalimentación y la competencia entre los distintos formatos de la novela. En periódicos contemporáneos es posible ver un anuncio de la venta del final de una obra que apenas había comenzado a serializarse en el periódico (La Gaceta Mercantil, $\mathrm{N}^{\circ}$ 6.764, 27 de abril de 1846: 3), la secuela de una obra que tuvo éxito en el folletín (La Gaceta Mercantil, N 7.631, 28 de abril de 1849: 4), e incluso, el remate de una edición debido a que la competencia la había editado en una modalidad más accesible. Es decir, la proliferación en la oferta demuestra que la venta de novelas, aun a mínima escala, se convirtió rápidamente en un negocio redituable, pero también competitivo. Eso mismo explicitó Pedro Ponce al especificar en un aviso que la publicación de "Los Siete Pecados Capitales" dependía de alcanzar una suscripción que "subvenga á los gastos de impresión" (DdlT, N 4930, 28 de febrero de 1848: 2). Tampoco se puede restar importancia al impacto en este mercado de la oferta ampliada del folletín del diario, que permitió el acceso a otra modalidad de entrega para la novela con precio más bajo. Los impresores mismos no perdieron oportunidad de resaltar este ánimo lector, siendo un lugar común en los avisos atribuir cada edición a la demanda popular. En Francia, los "periódicos para tenderos" fueron artífices de una expansión y diversificación del público lector mediante la invención del folletín (Rivera, 1971: 6). Si bien estos diagnósticos deben ser atemperados en el caso del Diario de la Tarde, la difusión de la novela indica que, cuanto menos, nos encontramos en los albores de la conformación de un "publico mesocrático" y ampliado (Poblete, 2016: 84). Todo denota que algo había cambiado en el pacto de lectura, y ya no había vuelta atrás.

\section{Conclusión}

A través de la exploración de una faceta poco conocida del Diario de la Tarde, un periódico sobre el cual aún pesa el mote de "adicto" con el que se adjetivan los papeles editados durante el largo segundo gobierno de Rosas sobre la provincia, no solo hemos aspirado intervenir en el debate acerca de la cronología de la prensa y su desarrollo, sino también llamar a una revisión más amplia acerca del mundo editorial y cultural del Buenos Aires de los 1840. Como ya han llamado la atención 


\section{EI Diario de la Tarde durante la década de 1840. Fait divers, folletín y lectura por entretenimiento en tiempos de Rosas}

investigadores como Hernán Pas, desarrollos en la prensa porteña que durante décadas se han asociado con las postrimerías del siglo XIX tuvieron en realidad su desembarco y adaptación local varios lustros antes, como prueba el caso de la fuente aquí analizada y otras publicaciones contemporáneas.

En el caso de los fait divers, debido a su heterogeneidad dictada por la "contaminación novelesca" de la cual nacieron, se torna difícil señalar una cronología tajante. Lo cierto es que existió una zona de experimentación sostenida tentativamente desde 1838 y a lo largo de los 1840, una trayectoria sutil, de avance y retroceso dentro del periódico, donde los títulos engañan y las características que se le asocian alternativamente divergen y se encuentran sin grandes anuncios editoriales ni transformaciones tipográficas. Hacia el último año de publicación, el recurso parece haber llegado a cierto grado de consolidación, apareciendo más definido y portando las características que Barthes le atribuye al género periodístico en su clásica definición.

Por su parte, el folletín y la novela por entrega irrumpen de manera más definida por la misma naturaleza tipográfica del mismo en 1846. Si bien la novela europea de folletín fue introducida en Buenos Aires por la importación de impresos producidos del otro lado del Atlántico específicamente para venderse en Hispanoamérica, no puede despreciarse el rol amplificador de las imprentas locales que replicaron (sin permiso) dichos productos, entre otros modos, mediante su inclusión en la prensa diaria. Al introducir en la prensa de mayor circulación y producción local a la novela por entregas, no solo modificó los modos en que los lectores porteños consumían esta literatura, sino también el lugar que tenía la lectura por entretenimiento dentro de las publicaciones periódicas, particularmente las diarias.

En las páginas del Diario de la Tarde, la consolidación de la novela por entregas dentro del folletín, así como la inclusión de los fait divers, modificaron sensiblemente que se pensaba por la propuesta editorial de un diario político y mercantil. En sintonía con lo que tentativamente delineamos como un contexto de eclosión en la sociabilidad urbana con respecto al consumo de entretenimiento, tal cual dejan adivinar fuentes y los pocos estudios secundarios al respecto, estos recursos formales abrieron camino a la resignificación del lugar de la lectura por entretenimiento en la prensa diaria. Fuera dentro de los límites del zócalo del folletín, o en la incipiente "contaminación novelesca" que propiciaba la “extranjerización” de las "Noticias Varias” y “Variedades”.

Cuando la prensa regreso luego Caseros se discutió mucho acerca del alcance y conveniencia de la libertad de prensa e impresores (pero, siempre, financiada por actores estatales). Lo que ya no estaba en discusión, como demuestra un episodio que involucró a Sarmiento, Mitre y otros jefes de redacción de la época relatado por Molina (2011: 45 y ss.), era que los fait divers, el folletín y, sobre todo, la novela por entregas, tenían un lugar asegurado en los periódicos porteños. La lectura por entretenimiento había llegado a la prensa para quedarse. 


\section{Diego Labra}

\section{Bibliografía}

Aguilar, G. (2003). The National Opera: A Migrant Genre of Imperial

Expansion 1. Journal of Latin American Cultural Studies, 12(1).

Barthes, R. (2003 [1964]). Estructura del "suceso". En Ensayo Críticos. Buenos Aires: Seix Barral.

Buonocore, D. (1969). Libros y bibliófilos durante la época de Rosas. Córdoba: Universidad Nacional de Córdoba.

Caimari, L. (2015). El mundo al instante. Noticias y temporalidades en la era del cable submarino (1860-1900). Redes, (40). Recuperado de https://ridaa.unq.edu.ar/bitstream/handle/20.500.11807/378/05$\underline{\text { R2015v21n40.pdf?sequence }=1 \text { \&isAllowed }=y}$

Chartier, R. (1994). Libros, lecturas y lectores en la Edad Moderna. Madrid: Alianza.

Chávez, F. (1972). Iconografía de Rosas y de la Federación: Nuevos aportes. Buenos Aires: Oriente

El Diario. edición extraordinaria. Buenos Aires, 1933.

Espósito, F. (2009). La emergencia de la novela en Argentina. La prensa, los lectores y la ciudad (1880-1890). La Plata: Al Margen.

Feyel, G. (2005). Prémices et épanouissement de la rubrique de faits divers (16311848). Les Cahiers du Journalisme, (14).

Fritzsche, P. (1996). Reading Berlin 1900. Cambridge, Massachusetts: Harvard University Press.

Galván Moreno, C. (1944). El Periodismo Argentino. Amplia y documentada historia desde sus orígenes hasta su presente. Buenos Aires: Editorial Claridad.

Gesualdo, V. (1983). Teatros del Buenos Aires antiguo. Buenos Aires: Librería Platero.

Goldgel, V. (2010). Caleidoscopios del saber. El deseo de variedad en las letras latinoamericanas del siglo XIX. Estudios. Revista de investigaciones literarias $y$ culturales, 18(36). Recuperado de https://biblat.unam.mx/hevila/EstudiosRevistadeinvestigacionesliterariasycultur ales/2010/vol18/no36/2.pdf 


\section{EI Diario de la Tarde durante la década de 1840. Fait divers, folletín y lectura por entretenimiento en tiempos de Rosas}

Guillamón, G. (2014). Reflexiones sobre música y política: lo visible y lo invisible de la cultura musical en las fuentes de principios de siglo XIX. Revista Electrónica de $\begin{array}{lllll}\text { Fuentes } y & \text { Archivos, (5). Recuperado de }\end{array}$ http://sedici.unlp.edu.ar/bitstream/handle/10915/100931/Reflexiones sobre m \%C3\%BAsica y pol\%C3\%ADtica lo visible y lo invisible de la \%22cultura musi cal\%22 en las fuentes de principios de siglo XIX.pdf-

PDFA.pdf?sequence $=1 \&$ isAllowed $=\mathrm{y}$

Iglesia, C. (2014). Echeverría: la patria literaria. En C. Iglesia \& L. El Jaber (dirs.), N. Jitrik (dir. gral.). La patria literaria, Vol. 1 de Historia Crítica de la Literatura Argentina. Buenos Aires: Emecé.

Laera, A. (2003). El tiempo vacío de la ficción: Las novelas argentinas de Eduardo Gutiérrez y Eugenio Cambaceres. Buenos Aires: Fondo de Cultura Económica.

Lettieri, A. (2006). La construcción de la República de la opinión. Buenos Aires frente al interior en la década de 1850. Buenos Aires: Prometeo.

Molina, E. (2009). El poder de la opinión pública. Trayectos y avatares de una nueva cultura política en el Río de la Plata, 1800-1852. Santa Fe: Universidad Nacional del Litoral.

Molina, H. (2011). Como crecen los hongos. La novela argentina entre 1838 y 1872. Buenos Aires: Teseo.

Pas, H. (2013). Sarmiento, redactor y publicista. Con textos recobrados de El Progreso (1842-1845) y La Crónica (1849-1850). Santa Fe: Ediciones UNL.

Pas, H. (2016). Variedades y escritura periódica. Notas para una historia del folletín en el Río de la Plata. En V. Delgado \& G. Rogers (eds.). Tiempos de papel: Publicaciones periódicas argentinas (siglos XIX-XX). La Plata: Universidad Nacional de La Plata. Facultad de Humanidades y Ciencias de la Educación .

Pas, H. (2018). Eugène Sue en Buenos Aires. Edición, circulación y comercialización del folletín durante el rosismo. Varia Historia, (64). Recuperado de https://ri.conicet.gov.ar/bitstream/handle/11336/95566/CONICET Digital Nro.d cf2c29b-0a1b-4aa3-8d83-3400c69c2557 A.pdf?sequence=2\&isAllowed=y

Pas, H. (2019). “El teatro de la opinión. Prensa política y lectura de después de la Revolución en el Río de la Plata". Historia y comunicación social, 24(2). Recuperado de https://revistas.ucm.es/index.php/HICS/article/view/66307/4564456552469 


\section{Diego Labra}

Pastormerlo, S. (2016). Sobre la primera modernización de los diarios en Buenos Aires. Avisos, noticias y literatura durante la Guerra Franco-Prusiana (1870)" En V. Delgado \& G. Rogers (eds.). Tiempos de papel: Publicaciones periódicas argentinas (siglos XIX-XX). La Plata: Universidad Nacional de La Plata. Facultad de Humanidades y Ciencias de la Educación.

Poblete, J. (2016). De la lectura como práctica histórica en América Latina: la primera época colonial y el siglo XIX. Cuadernos de Literatura, (39). Recuperado de https://dialnet.unirioja.es/descarga/articulo/5271701.pdf

Rivera, J. (1971). El folletín y la novela popular. Buenos Aires: Centro Editor de América Latina.

Sarlo, B. (1985). El imperio de los sentimientos: Narraciones de circulación periódica en la Argentina [1917-1927]. Buenos Aires: Catálogos.

Weill, G. (1962). El periódico. Orígenes, evolución y función de la prensa periódica. México: UTEHA.

\section{Fuentes}

El Lucero. Buenos Aires, 1829-1832.

La Moda. Buenos Aires, 1837-1838.

La Gaceta Mercantil. Buenos Aires, 1838-1852.

Diario de la Tarde. Buenos Aires, 1838-1852.

Diario de Avisos. Buenos Aires, 1849-1852.

Recibido: 27/10/2020

Evaluado: $11 / 12 / 2020$

Versión Final: 06/01/2021 